\title{
A central role of Cwc25 in spliceosome dynamics during the catalytic phase of pre-mRNA splicing
}

\author{
CHI-KANG TSENG, ${ }^{1,2}$ CHE-SHENG CHUNG, ${ }^{1}$ HSIN-CHOU CHEN, ${ }^{3}$ and SOO-CHEN CHENG \\ Institute of Molecular Biology, Academia Sinica, Taipei, Taiwan 115, Republic of China
}

\begin{abstract}
Splicing of precursor mRNA occurs via two consecutive steps of transesterification reaction; both require ATP and several proteins. Despite the energy requirement in the catalytic phase, incubation of the purified spliceosome under proper ionic conditions can elicit competitive reversible transesterification, debranching, and spliced-exon-reopening reactions without the necessity for ATP or other factors, suggesting that small changes in the conformational state of the spliceosome can lead to disparate chemical consequences for the substrate. We show here that Cwc25 plays a central role in modulating the conformational state of the catalytic spliceosome during normal splicing reactions. Cwc25 binds tightly to the spliceosome after the reaction and is then removed from the spliceosome, which normally requires DExD/H-box protein Prp16 and ATP hydrolysis, to allow the occurrence of the second reaction. When deprived of Cwc25, the purified first-step spliceosome catalyzes both forward and reverse splicing reactions under normal splicing conditions without requiring energy. Both reactions are inhibited when Cwc25 is added back, presumably due to the stabilization of first-step conformation. Prp16 is dispensable for the second reaction when splicing is carried out under conditions that destabilize Cwc25. We also show that the purified precatalytic spliceosome can catalyze two steps of the reaction at a low efficiency without requiring Cwc25, Slu7, or Prp18 when incubated under proper conditions. Our study reveals conformational modulation of the spliceosome by Cwc25 and Prp16 in stabilization and destabilization of first-step conformation, respectively, to facilitate the splicing process.
\end{abstract}

Keywords: spliceosome; splicing catalysis; Cwc25

\section{INTRODUCTION}

Pre-mRNA splicing takes place on the spliceosome, which is constituted of five small nuclear RNAs and numerous protein factors. The spliceosome and self-splicing group II introns share the same chemical mechanism for the reaction they catalyze and similar RNA structural elements at the catalytic cores (Villa et al. 2002; Toor et al. 2008; Fica et al. 2013), but many protein factors are required for assembly and modulation of the RNA structures on the spliceosome. The spliceosome is highly dynamic both conformationally and compositionally, and undergoes sequential structural rearrangements throughout the entire pathway (Wahl et al. 2009; Will and Lührmann 2011). Structural changes of the spliceosome are mediated by DExD/H-box ATPases (Staley and Guthrie 1998; Linder and Jankowsky 2011). Two DExD/H-box ATPases are required for the catalytic phase of the spliceosome pathway. In the first catalytic step, Prp2

\footnotetext{
${ }^{1}$ These authors contributed equally to this work.

${ }^{2}$ Present address: Stowers Institute for Medical Research, Kansas City, MO 64110, USA

${ }^{3}$ Present address: Green Technology Research Institute, CPC Corporation, Kaohsiung, Taiwan 812, Republic of China

Corresponding author: mbscc@ccvax.sinica.edu.tw

Article is online at http://www.rnajournal.org/cgi/doi/10.1261/rna.059204. 116.
}

promotes destabilization of $\mathrm{U} 2$ components SF3a/b (Warkocki et al. 2009; Lardelli et al. 2010) to allow the binding of Cwc25, which is required for the first reaction and becomes stably bound to the spliceosome after the reaction (Chiu et al. 2009; Warkocki et al. 2009). Yju2 is also required for the recruitment of Cwc25 to the spliceosome, and together with Cwc25, is destabilized from the spliceosome after the first reaction (Liu et al. 2007b; Chiu et al. 2009). In the second step, Prp16 mediates destabilization of Yju2 and Cwc25 to allow the second reaction (Tseng et al. 2011), promoted by Slu7, Prp18, and Prp22 (Horowitz and Abelson 1993a,b; Ansari and Schwer 1995; Jones et al. 1995; Schwer and Gross 1998).

Based on a wealth of genetic and crosslinking data, a twostate model was proposed for the catalytic spliceosome which suggests that the conformations of the spliceosome supporting the two catalytic steps are in competition (Query and Konarska 2004; Liu et al. 2007a). Despite the ATP requirement for the transition from the first to second step, the (C) 2017 Tseng et al. This article is distributed exclusively by the RNA
Society for the first 12 months after the full-issue publication date (see
http://rnajournal.cshlp.org/site/misc/terms.xhtml). After 12 months, it is avail-
able under a Creative Commons License (Attribution-NonCommercial 4.0
International), as described at http://creativecommons.org/licenses/by-nc/4.0/. 


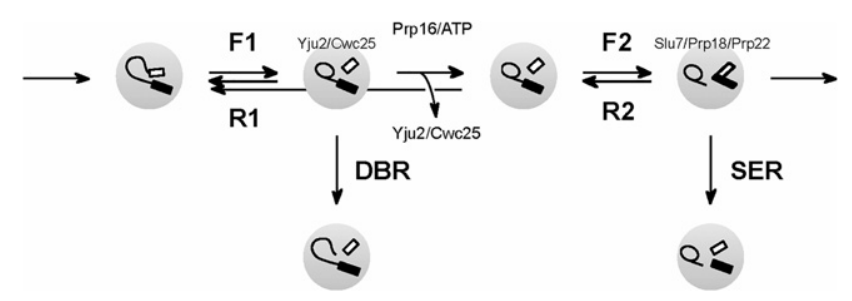

FIGURE 1. Schematic of the spliceosome catalytic steps showing different chemical reactions that the spliceosome can catalyze. (F1) First forward reaction; (R1) reverse of the first reaction; (F2) second forward reaction; (R2) reverse of the second reaction; (DBR) debranching reaction; (SER) spliced-exon reopening reaction.

purified catalytic spliceosomes could catalyze reverse transesterification of the first (R1) and second step (R2), as well as hydrolytic debranching (DBR) and spliced-exon reopening (SER) reactions under specific ionic conditions (Fig. 1; Tseng and Cheng 2008, 2013). This supports the notion that the conformation of the spliceosome can fluctuate between different catalytic states, influenced by the ionic environment, and that closely related conformational states of the spliceosome might be guiding the type of chemical reaction to catalyze.

We have recently shown, by crosslinking analysis, that Yju2 directly binds to U2 snRNA, contacting the RNA near the branch-binding region (Chiang and Cheng 2013), and Cwc25 binds to the pre-mRNA near the branch site in the catalytic spliceosome (Chen et al. 2013). Modifying the $\mathrm{N}$-terminal structure of Yju2 or Cwc25 by adding a tag completely inhibits the DBR reaction under all conditions (Tseng and Cheng 2013), indicating that the catalytic potentials of the spliceosome are not only influenced by the ionic environment, but also affected by the structure of the proteins binding at or near the catalytic center. Supportively, recent structural determination of the catalytic first-step spliceosome revealed extensive interactions of both Yju2 and Cwc25 with the active site of the spliceosome. The $\mathrm{N}$ terminus of Yju2 wraps around the branch helix and also interacts with the $5^{\prime}$ splice site. The $\mathrm{N}$ terminus of Cwc25 is inserted into the widened major groove of the bulged branch helix and also forms multiple contacts with the branch site (Galej et al. 2016; Wan et al. 2016). Although both N-terminally tagged Yju2 and Cwc25 block the DBR reaction, only $\mathrm{N}$-terminally tagged Cwc25 also strongly enhances the R1 reaction, suggesting that these two proteins may affect the conformation of the spliceosome in different ways (Tseng and Cheng 2013).

Here we show that Cwc25 plays a crucial role in modulating the conformation of the catalytic spliceosome. We have developed a method to purify the Cwc25-lacking post-firststep spliceosome. The purified spliceosome could catalyze the splicing reaction in both directions, reverse of first step (R1) and forward of second step (F2), without needing Prp16 or any other factor. Adding back Cwc25 inhibited both reactions, suggesting that Cwc25 binding stabilizes the post-first-step conformation. Components of the Prp19-associated complex (NTC), Isy1/Ntc30 and Ntc20, stabilize the association of Cwc25 with the spliceosome, and their absence bypasses the requirement of Prp16 for the second step. We also show that not only are the chemical reactions reversible on the spliceosome, the binding of Cwc25 and Yju2 to the spliceosome is also reversible. Our results reveal remarkable malleability of the spliceosome in the catalytic phase, and an important role of Cwc25 in modulating the conformation of the spliceosome and facilitating the splicing reaction during catalytic steps.

\section{RESULTS}

\section{Tagging at the $\mathrm{N}$ terminus of Cwc25 destabilizes its association with the spliceosome}

We have previously shown that when the affinity-purified first-step spliceosome assembled in the absence of Prp16 was incubated at $25^{\circ} \mathrm{C}$, the presence of four copies of the V5-tag at the $\mathrm{N}$ terminus of Cwc25 (4V5-Cwc25) strongly biased the reaction toward the reverse reaction (R1) (Tseng and Cheng 2013), as also shown in Figure 2A. When the spliceosome assembled in Prp16-depleted 4V5-Cwc25 extracts was isolated by precipitation with anti-V5 antibody (lane 2) and then incubated at $25^{\circ} \mathrm{C}$, the majority of lariat-intronexon 2 was converted to pre-mRNA under all conditions (lanes 3-8). Kinetic analysis revealed that the reverse reaction was fast and proceeded to near completion within a few minutes in the presence of $50 \mathrm{mM}$ or $150 \mathrm{mM}$ of $\mathrm{KCl}$ either at $\mathrm{pH}$ 6.8 or $\mathrm{pH} 8.8$, but was slightly slower in the absence of $\mathrm{KCl}$, particularly at pH 6.8 (Supplemental Figs. S1, S2). The mechanism for the strong R1 preference was not fully understood. Since Cwc25 binds to the spliceosome after Prp2-mediated destabilization of SF3a/b and becomes stably associated with the spliceosome after the first reaction (Chiu et al. 2009; Ohrt et al. 2012), the binding of Cwc25 may promote or stabilize post-catalytic conformation. We speculated that the V5-tag present at the $\mathrm{N}$ terminus might interfere with the interaction of Cwc25 with the spliceosome such that Cwc25 comes off easily upon incubation, leading to a switch of the conformation back to the precatalytic state.

Possible destabilization of 4V5-Cwc25 was examined by analyzing the pellet and supernatant fractions after incubation of the spliceosome precipitated with anti-V5 antibody, as outlined in Figure 2B. The presence of the spliceosome in the supernatant indicates dissociation of $\mathrm{Cwc} 25$ from the spliceosome. As shown in Figure 2C, when the spliceosome was incubated in the presence of $50 \mathrm{mM} \mathrm{KCl}$ at $\mathrm{pH} 6.8$ or 8.8 (lanes 9-14), the majority of the splicing intermediates was converted to pre-mRNA (compare lanes 9 and 12 with lane 2), which was present primarily in the supernatant fractions (lanes 11,14). Both R1 reaction and Cwc25 dissociation occurred more readily at $\mathrm{pH} 8.8$ than at $\mathrm{pH} 6.8$. In the absence of $\mathrm{KCl}$ (lanes 3-8), 4V5-Cwc25 remained stably bound 
A

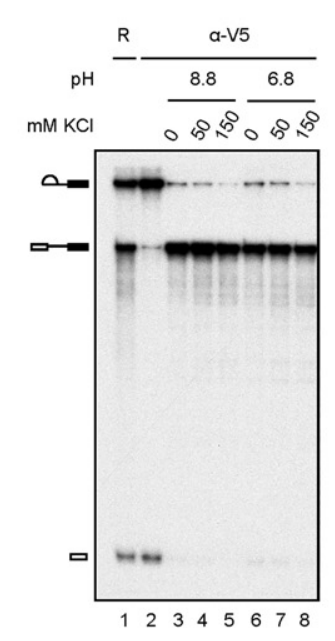

B

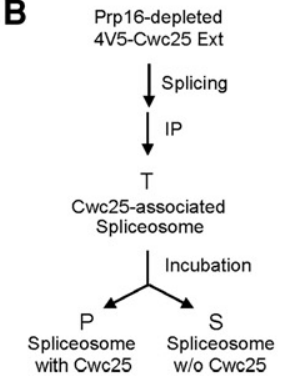

E

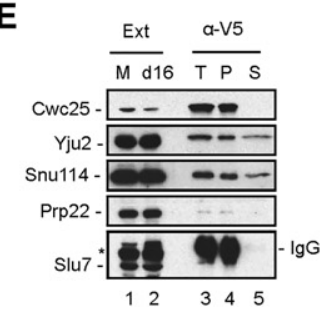

C

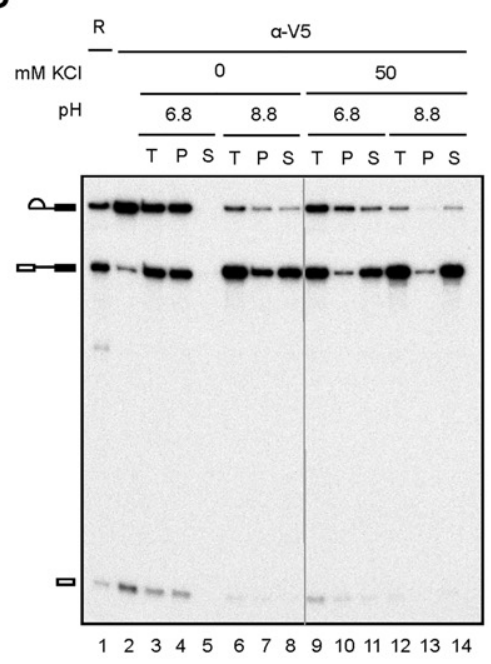

D

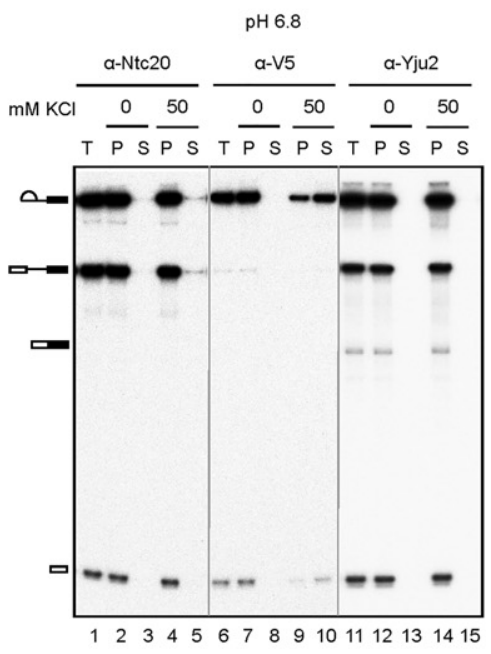

FIGURE 2. Tagging Cwc25 at the $\mathrm{N}$ terminus destabilizes Cwc25 from the spliceosome and promotes reverse splicing. Splicing was carried out in Prp16-depleted 4V5-Cwc25 extracts using actin ACAC pre-mRNA. (A) The spliceosome was precipitated with anti-V5 antibody (lane 2) and then incubated for $60 \mathrm{~min}$ in a buffer containing $10 \mathrm{mM}$ Tris- $\mathrm{HCl}$ and $8 \mathrm{mM} \mathrm{MgCl}_{2}$ with indicated $\mathrm{pH}$ and $\mathrm{KCl}$ concentrations. (B-E) The spliceosomes were isolated by immunoprecipitation and chased by incubation in a buffer containing $10 \mathrm{mM}$ Tris- $\mathrm{HCl}$ of indicated $\mathrm{pH}$ and salt concentrations for all the following experiments. (B) Experimental procedure. $(C)$ The spliceosome was precipitated with anti-V5 antibody (lane 2), and the pellet and supernatant fractions were separated after incubation for $20 \mathrm{~min}$ in a buffer containing $10 \mathrm{mM}$ Tris- $\mathrm{HCl}$ and $1 \mathrm{mM} \mathrm{MgCl}_{2}$ with indicated pH and $\mathrm{KCl}$ concentrations. (D) The spliceosome was precipitated with anti-Ntc20 (lane 1), anti-V5 (lane 6), or anti-Yju2 antibody (lane 11) and then incubated for $20 \mathrm{~min}$ in a buffer containing $10 \mathrm{mM}$ Tris- $\mathrm{HCl}, \mathrm{pH} 6.8$ without or with $50 \mathrm{mM} \mathrm{KCl}$, and separated into supernatant and pellet fractions. (E) Western blotting of mock-treated (lane 1) or Prp16-depleted (lane 2) extracts, the precipitated spliceosome (lane 3), and the pellet (lane 4) and supernatant (lane 5) fractions after incubation of the spliceosome in the presence of $50 \mathrm{mM} \mathrm{KCl}$. A nonspecific band in the extract from crossreaction with anti-Slu7 antibody is indicated by $\left(^{*}\right)$. $(\mathrm{R})$ One-tenth of the reactions used for immunoprecipitation; $(\mathrm{T})$ total precipitates; $(\mathrm{P})$ pellet fraction; (S) supernatant fraction; (Ext) extracts; (M) mock-treated; (d16) Prp16-depleted.

to the spliceosome at $\mathrm{pH} 6.8$ (lanes 4,5), but more than half of $4 \mathrm{~V} 5-\mathrm{Cwc} 25$ was released from the spliceosome at $\mathrm{pH} 8.8$ (lanes 7,8). These results indicate that stable association of $4 \mathrm{~V} 5$-Cwc25 with the spliceosome is sensitive to both salt and $\mathrm{pH}$. The fact that both the reverse reaction and dissociation of $4 \mathrm{~V} 5-\mathrm{Cwc} 25$ are preferred at higher $\mathrm{pH}$ and in the presence of $\mathrm{KCl}$ suggests that the binding of $\mathrm{Cwc} 25$ may disfavor the reverse reaction. Nevertheless, dissociation of 4 V5-Cwc25 from the spliceosome is not essential for the reverse reaction to take place as the reaction also occurred at $\mathrm{pH} 6.8$ in the absence of $\mathrm{KCl}$ when $4 \mathrm{~V} 5-\mathrm{Cwc} 25$ remained bound to the spliceosome (lane 4), suggesting that releasing $4 \mathrm{~V} 5-\mathrm{Cwc} 25$ is not a prerequisite for the reverse reaction.

We have previously shown that Prp16 has an ATP-independent function in stabilizing the association of Cwc25 with the spliceosome, and the ATPase mutant of Prp16 increases splicing of branchpoint mutants (Tseng et al. 2011). Nevertheless, Prp16 did not stabilize the 4V5-Cwc25 on the post-first-step spliceosome to a large extent upon incubation of the purified spliceosome (Supplemental Fig. S3). Besides Cwc25, Yju2 is also required for the first catalytic reaction (F1) after the spliceosome is activated (Liu et al. 2007b). Yju2 interacts with NTC components Clf1/Ntc77 and Syf1/ $\mathrm{Ntc} 90$ and can be recruited to the spliceosome prior to the action of Prp2 (Liu et al. 2007b). In contrast, Cwc25 is recruited to the spliceosome only after Prp2 action, and only in the presence of Yju2 (Chiu et al. 2009). To see whether tagging Cwc25 at the $\mathrm{N}$ terminus would also affect the association of Yju2 with the spliceosome, we carried out the splicing reaction in Prp16-depleted 4V5-Cwc25 extracts and purified the spliceosome by precipitation of the reaction mixture with antibody against Ntc20, Yju2, or V5 for Cwc25. The purified spliceosome was incubated at $\mathrm{pH} 6.8$, with or without $50 \mathrm{mM}$ $\mathrm{KCl}$, but in the absence of $\mathrm{Mg}^{2+}$ to prevent catalysis (Fig. 2D). The supernatant and pellet fractions were separated and examined for the presence of the spliceosome. The result shows that both Ntc20 and Yju2 remained stably associated with the spliceosome after incubation (lanes 4,5 and 14,15), whereas $>70 \%$ of $4 \mathrm{~V} 5$-Cwc25 was separated from the spliceosome (lanes 9,10). Western blotting of the spliceosome purified with anti-V5 antibody confirmed that the spliceosome released in the supernatant fraction contained no Cwc25 but contained Yju2 and Snu114 (Fig. 2E, lane 5). Furthermore, the purified spliceosome contained no significant amounts of Slu7 or Prp22 (lane 3). These results demonstrate that 4V5-Cwc25 is prone to dissociate from the spliceosome upon incubation independent of the reverse reaction whether in association with the pre-mRNA or with splicing intermediates. 
A

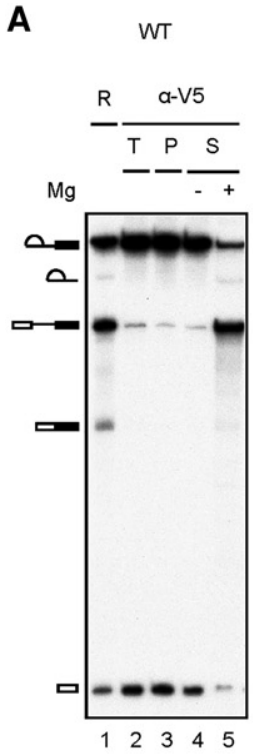

B

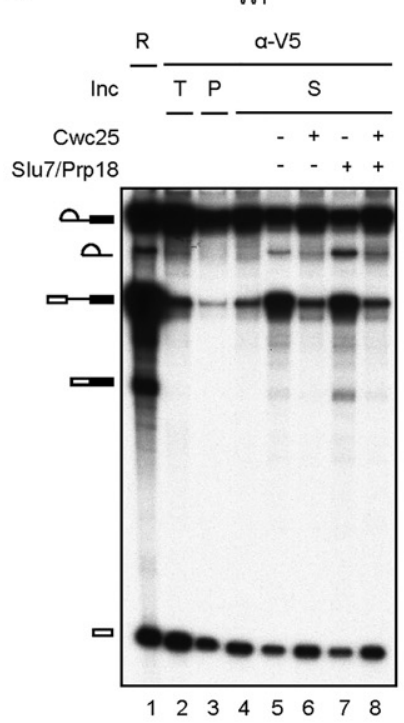

C

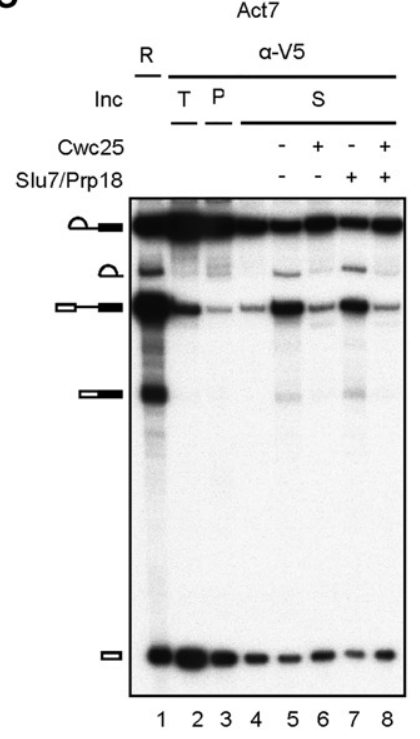

D

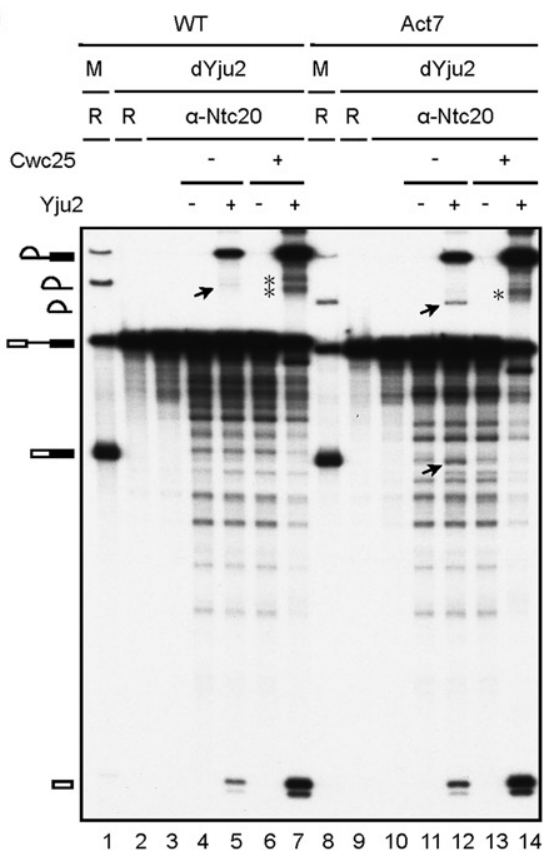

FIGURE 3. Cwc25 inhibits both forward and reverse reactions. (A) Splicing was carried out in Prp16-depleted 4V5-Cwc25 extracts using wild-type actin pre-mRNA (lane 1), and the spliceosome was precipitated with anti-V5 antibody (lane 2). The isolated spliceosome was incubated for 10 min in a buffer containing $10 \mathrm{mM}$ Tris- $\mathrm{HCl}, \mathrm{pH} 6.8$ and $50 \mathrm{mM} \mathrm{KCl}$, and the pellet (lane 3) and supernatant (lane 4) fractions were separated. The supernatant fraction was further incubated for 30 min following the addition of $2.4 \mathrm{mM} \mathrm{Mg}^{2+}$ (lane 5). (B,C) Splicing was carried out in Prp16-depleted 4V5Cwc25 extracts using wild-type $(B)$ or Act7 $(C)$ actin pre-mRNA (lane 1), and the spliceosome was isolated and chased as in $A$ (lane 5), with the addition of $25 \mathrm{nM}$ Cwc25 (lane 6), or $50 \mathrm{nM}$ Slu7/Prp18 (lane 7), or both Cwc25 and Slu7/Prp18 (lane 8). (D) Splicing was carried out in mocktreated (lanes 1,8) or Yju2-depleted (lanes 2-7 and 9-14) 4V5-Cwc25 extracts using wild-type (lanes 1-7) or Act7 (lanes 8-14) actin pre-mRNA. The spliceosome was precipitated with anti-Ntc20 antibody (lanes 3,10) and then incubated in a buffer containing $60 \mathrm{mM} \mathrm{KPO}$, $\mathrm{pH}_{7.0}, 4 \mathrm{mM}$ $\mathrm{MgCl}_{2}$, and $0.5 \mathrm{mM} \mathrm{MnCl}_{2}$ with or without the addition of $25 \mathrm{nM} \mathrm{Cwc25}$ and/or Yju2. (R) Reaction; (T) total; (S) supernatant; (P) pellet; (dYju2) Yju2-depleted; arrows mark spliced products; (stars) 3'-tail-trimmed lariat-intron-exon 2.

\section{The Cwc25-free first-step spliceosome can catalyze both forward and reverse reactions}

Although the dissociation of $4 \mathrm{~V} 5$-Cwc25 is not a prerequisite for the reverse reaction, it is still possible that the spliceosome favors the precatalytic conformation in the absence of Cwc25. To confirm that, the spliceosome formed in Prp16-depleted $4 \mathrm{~V} 5$-Cwc25 extracts was isolated by precipitation with antiV5 antibody (Fig. 3A, lane 2) and then incubated at $\mathrm{pH} 6.8$ in the presence of $50 \mathrm{mM} \mathrm{KCl}$, but without $\mathrm{Mg}^{2+}$, to allow dissociation of Cwc25 (lanes 3,4). After removal of the pellet fraction, the Cwc25-free spliceosome in the supernatant fraction was incubated in a buffer containing $60 \mathrm{mM} \mathrm{KPO}_{4}, \mathrm{pH}$ 7.0 and $4 \mathrm{mM} \mathrm{MgCl}_{2}$ (lane 5) to see whether the reverse reaction could take place. As expected, the majority of lariat-intron-exon 2 was converted to pre-mRNA (compare lanes 4 and 5), confirming that the reverse reaction could occur efficiently on the Cwc25-free spliceosome. Interestingly, a small amount of mature mRNA and lariat-intron was also observed, indicative of the occurrence of the second reaction. This strongly suggests that the Cwc25-free first-step spliceosome exists in a dynamic conformational state, fluctuating between precatalytic, first-step, and second-step conformations to catalyze transesterification reactions in both forward and reverse directions, with a strong tendency toward the precatalytic state.

In normal splicing reactions, Cwc25 binds tightly to the spliceosome after lariat formation and requires Prp16 and ATP for its dissociation from the spliceosome before the second catalytic reaction can take place (Tseng et al. 2011). Yju2 is also destabilized during this process. Our data show that the presence of an extra segment at the $\mathrm{N}$ terminus of Cwc25 destabilizes its binding and facilitates its release from the spliceosome without affecting the association of Yju2 with the spliceosome (Fig. 2D). Under this condition, the second reaction could take place without the need of second-step factors Slu7/Prp18, although only at a low efficiency. Conceivably, Cwc25 stabilizes first-step conformation, and Slu7/Prp18 may stabilize second-step conformation.

To see the effect of Cwc25 and Slu7/Prp18, we performed the experiment in a similar way, with Cwc25 or Slu7/Prp18 added to the spliceosome prior to incubation with $\mathrm{Mg}^{2+}$ (Fig. 3B). Since tagging Cwc25 at its $\mathrm{N}$ terminus perturbed the reaction, recombinant Cwc25 with a His-tag at the carboxyl terminus was used for this experiment. As expected, both forward and reverse reactions were inhibited in the presence of Cwc25 (lane 6), suggesting that Cwc25 stabilizes the post-first-step conformation and prevents the spliceosome 
from switching to other conformational states. However, addition of Slu7 and Prp18 did not inhibit the reverse reaction to a large extent, although it did promote a small level of the second reaction (lane 7). Prp22 was not added, since it was shown and also observed by us not to be required for the second reaction (Ohrt et al. 2013). When Cwc25 and Slu7/Prp18 were both present, the forward and reverse reactions were both inhibited (lane 8 ), indicating a dominant effect of Cwc25 in stabilizing the first-step conformation. These results suggest that although the conformation of the spliceosome can fluctuate between these three states in the absence of Cwc25, it strongly favors the precatalytic state and disfavors the second step. The presence of Slu7/Prp18 promotes the second step only to a small extent, but does not prevent the spliceosome from switching to the precatalytic state.

Transition to the second step requires positioning of the $3^{\prime}$ splice site at the catalytic center, and likely demands more changes in the structure of the spliceosome. Slu7 and Prp18 presumably facilitate positioning of the $3^{\prime}$ splice site and are dispensable when the distance between the branch site and $3^{\prime}$ splice site is shortened to 7 nucleotides (nt) for actin pre-mRNA (Act7) (Brys and Schwer 1996). However, without the addition of Slu7/Prp18, only a slightly higher level of the second reaction was observed with Act7 (Fig. 3C, lane 5), suggesting that additional factors required for promoting positioning of the $3^{\prime}$ splice site might be absent on the purified spliceosome or the presence of Yju2 might interfere with the second-step reaction.

We previously demonstrated that the first splicing reaction could take place without Cwc25 when the purified spliceosome assembled in Cwc25-depleted extracts was incubated in the presence of $\mathrm{Mn}^{2+}$ (Chiu et al. 2009). We therefore examined whether the reaction could proceed through two catalytic steps to generate products in the absence of second-step factors, and also used Act7 pre-mRNA to see whether more second reactions could be induced. Spliceosomes were assembled in Yju2-depleted extracts, purified by precipitation with anti-Ntc20 antibody, and then incubated in the presence of $\mathrm{Mn}^{2+}$ with or without the addition of Yju2 and/or Cwc25 (Fig. 3D). The spliceosome purified under this condition presumably is stalled after Prp2 action and contains no Cwc25 (Liu et al. 2007b; Chiu et al. 2009). In the presence of Yju2, spliceosomes assembled on either wild-type or Act7 pre-mRNA could bypass the requirement of Cwc25 to promote the first reaction upon incubation with $\mathrm{Mn}^{2+}$ (lanes $5,12)$. As expected, the spliceosome could further catalyze the second reaction, and this was more prominently the case with Act7 (lane 12) than with wild-type pre-mRNA (lane 5). In the presence of Cwc25, although the efficiency of the first reaction was enhanced, the second reaction was inhibited (lanes $6,7,13,14)$. Instead, products possibly generated from the debranching reaction were observed. These results indicate that after Prp2-mediated destabilization of SF3a/b and in the presence of Yju2, the splicing reaction can proceed through the first to the second step in the absence of Cwc25 and second-step factors under conditions that allow the spliceosome to change its conformation, although at a low efficiency. Cwc25 interrupts the conformational dynamics and prevents the pathway from progressing to the second step.

\section{Dynamic interactions of Cwc25 and Yju2 with the first-step spliceosome in competition with Slu7}

The fact that the addition of Cwc25 to the first-step Cwc25free spliceosome inhibited both forward and reverse reactions suggests that Cwc25 can rebind to the spliceosome after its release. To confirm reassociation of Cwc25 with the spliceosome, the spliceosome was assembled with ACAC pre-mRNA and arrested prior to the binding of secondstep factors using Slu7-depleted Cwc25-HA extracts. The association of Cwc25 with the spliceosome was examined by precipitation with anti-HA antibody. For comparison, total activated spliceosomes were precipitated with anti-Ntc20 antibody, and the Prp22-associated spliceosome was precipitated with anti-Prp22 antibody (Fig. 4A). To retain Cwc25 on the spliceosome, ATP was depleted after the reaction and prior to immunoprecipitation. In mock-treated extracts, regardless of ATP depletion (lanes 1-8), Cwc25 was not seen to significantly associate with the spliceosome (lanes 3,7 ) as opposed to Prp22 (lanes 4,8), indicating the majority of the spliceosome had progressed past the first step, leading to Prp22 association. In Slu7-depleted extracts (lanes 9-16), while the level of Cwc25 associated with the spliceosome was low without ATP depletion (lane 11), a much larger amount of Cwc25 accumulated on the spliceosome after ATP depletion (lane 15). Prp22 is known to require Slu7 for binding to the spliceosome (James et al. 2002) and was not seen to associate with the spliceosome in Slu7-depleted extracts. This result indicates that Cwc25 can reassociate with the spliceosome after Prp16-mediated dissociation in the absence of Slu7. Cwc25 may cycle through association and dissociation in the presence of ATP, and therefore only a small amount of Cwc25 was detected in association with the spliceosome, and only after ATP was depleted could significant association of Cwc25 be observed. Similarly, Yju2 could also reassociate with the spliceosome in the absence of Slu7 (Supplemental Fig. S4).

The fact that reassociation of Cwc25 or Yju2 could be observed in Slu7-depleted extracts suggests that the presence of Slu7/Prp18/Prp22 might prevent reassociation of Cwc25 so that the pathway can progress. We examined reassociation of Cwc25 in the presence of Slu7 by adding back Slu7 during the incubation after depletion of ATP (Fig. 4B). Indeed, the amounts of Yju2 and Cwc25 associated with the spliceosome were greatly reduced in the presence of Slu7 (compare lanes 13 and 18, and lanes 14 and 19). Quantification of the result revealed a reduction of around 50\% of both Yju2 and Cwc25 association upon the addition of Slu7 (Fig. 4C). 

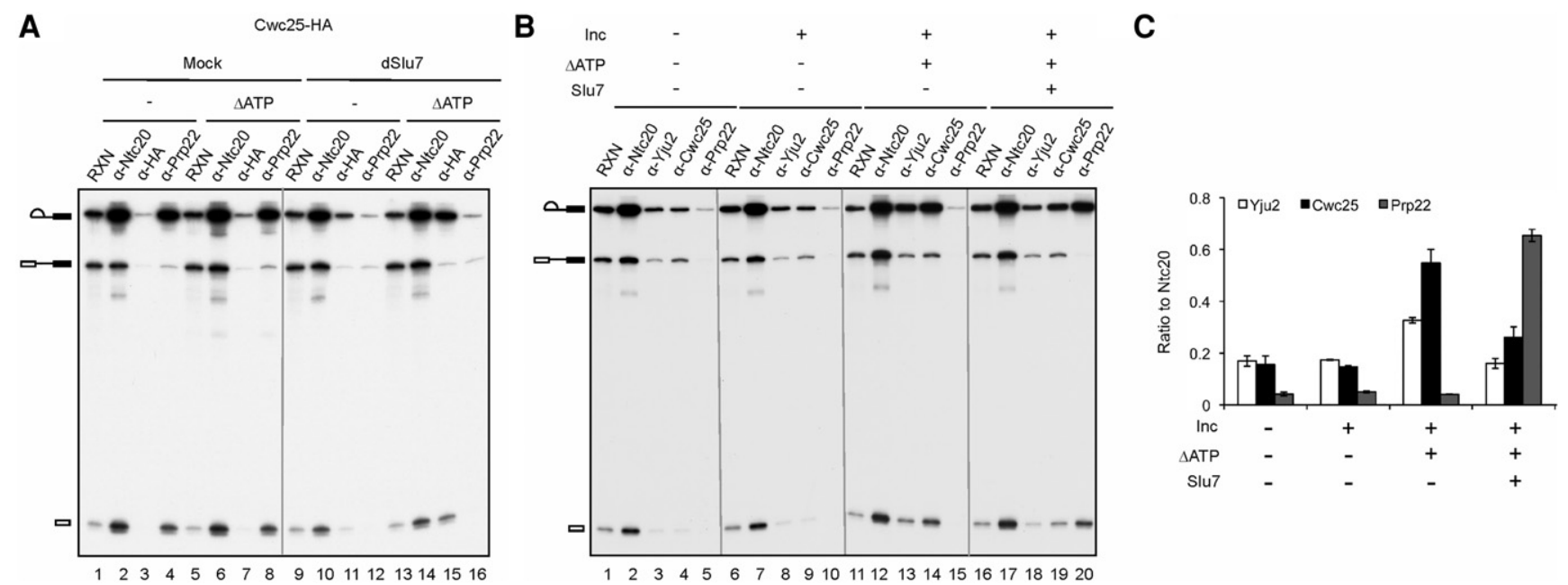

FIGURE 4. Reversible binding of Cwc25 and Yju2 to the post-first-step spliceosome in competition with Slu7. (A) Splicing was carried out in mocktreated (lanes 1-8) or Slu7-depleted (lanes 9-16) Cwc25-HA extracts. The reaction mixtures were further incubated for 5 min without (lanes 1-4 and 9-12) or with (lanes 5-8 and 13-16) the addition of $10 \mathrm{mM}$ glucose, and then precipitated with anti-Ntc20, anti-HA, or anti-Prp22 antibody. (B) Splicing was carried out in Slu7-depleted extracts. The reaction mixtures were further incubated for 5 min without (lanes 6-10) or with (lanes 11-20) the addition of $10 \mathrm{mM}$ glucose and $200 \mathrm{nM}$ of recombinant Slu7 (lanes 16-20). The reaction mixtures were then precipitated with antiNtc20, anti-Yju2, anti-Cwc25, or anti-Prp22 antibody. $(C)$ The amounts of lariat IVS-E2 were quantified with a phosphoimager, and those associated with Yju2, Cwc25 and Prp22 relative to that associated with Ntc20 were plotted in a bar graph.

\section{Destabilization of Cwc25 bypasses the Prp16 requirement for the second catalytic step}

Our results suggested that Cwc25 might be the main reason that Prp16 is required for the second catalytic reaction. In this case, defects in Cwc25 or in the spliceosome that reduce the affinity of Cwc25 for the spliceosome are expected to bypass the requirement of Prp16 for the second step. It has been reported that deletion of ISY1/NTC30, which encodes a component of the NTC, suppresses the growth defect of prp16-302 mutant (Villa and Guthrie 2005). We speculated that the absence of Ntc30 might affect stable association of Cwc25 with the spliceosome, and consequently Cwc25 comes off more easily without needing Prp16. We tested this hypothesis in the in vitro splicing system using ntc30 $\Delta$ extracts (Supplemental Fig. S5). Splicing was carried out in Prp16-depleted wild-type (lane 4) or ntc30 (lane 10) extracts (Fig. 5A). The amount of lariat IVS-E2 and mRNA was quantified by a phosphorimager, and the ratio of the second reaction to total reaction was assessed. Molar amount of the second reaction was calculated as the molar amount of mRNA produced, and total reactions as the sum of lariat-IVS-E2 and mRNA. Although the splicing activity of ntc30 $\Delta$ extracts was lower than that of wild-type, the fraction of the second reaction was higher in Prp16-depleted extracts (Fig. 5B, upper panel), indicating that without Prp16 the reaction could proceed to the second step more easily in the absence of Ntc30, consistent with the previously observed suppression phenotype. To assess the stability of Cwc25 association with the spliceosome in the absence of Ntc30, the ratio of Cwc25-asssociated spliceosome to total activated spliceosomes in wild-type and ntc30 $\Delta$ extracts was measured. Splicing reaction mixtures were precipitated with anti-Ntc20 antibody for total activated spliceosome (Fig. 5A, lanes 5,11) or with anti-Cwc25 antibody for Cwc25-associated spliceosome (Fig. 5A, lanes 6,12). The ratio of the Cwc25-associated spliceosome to total activated spliceosomes was lower in ntc30 $\Delta$ than in wild-type extracts (Fig. 5B, lower panel), suggesting destabilization of Cwc25 in the absence of Ntc30. To avoid potential differences from different extracts or extracts prepared from different strains, we used the ntc30 $\Delta$ extract and added back recombinant Ntc30 to assess the difference in the ratio of the second reaction and Cwc25 association (Fig. 5C,D). Indeed, the fraction of the second reaction was reduced from 0.46 to 0.28 upon addition of $\mathrm{Ntc} 30$, and the relative amount of Cwc25 association increased from 0.15 to 0.24 . These results support our hypothesis that suppression of prp16 growth defect in $n t c 30 \Delta$ cells is at least in part due to destabilization of Cwc25.

Ntc30 and Ntc20 are both components of the Prp19-associated complex, and both interact with $\mathrm{Ntc90}$, Ntc85, and Ntc77, but not with each other (Tsai et al. 1999; Chen et al. 2002). Deletion of either gene shows no growth defect, but deletion of both severely impairs growth, suggesting functional redundancy of these two genes. It is possible that Ntc20 might also contribute to stabilization of Cwc25. We examined whether depletion of Ntc20 could also bypass the Prp16 requirement for the second step, and whether depletion of both Ntc30 and Ntc20 would have an additive effect (Supplemental Fig. S6A). Indeed, the ratio of the second to the total reaction in ntc20 $\Delta$ extracts was also higher than in wild-type although not as high as in ntc30 $\Delta$, but was even 

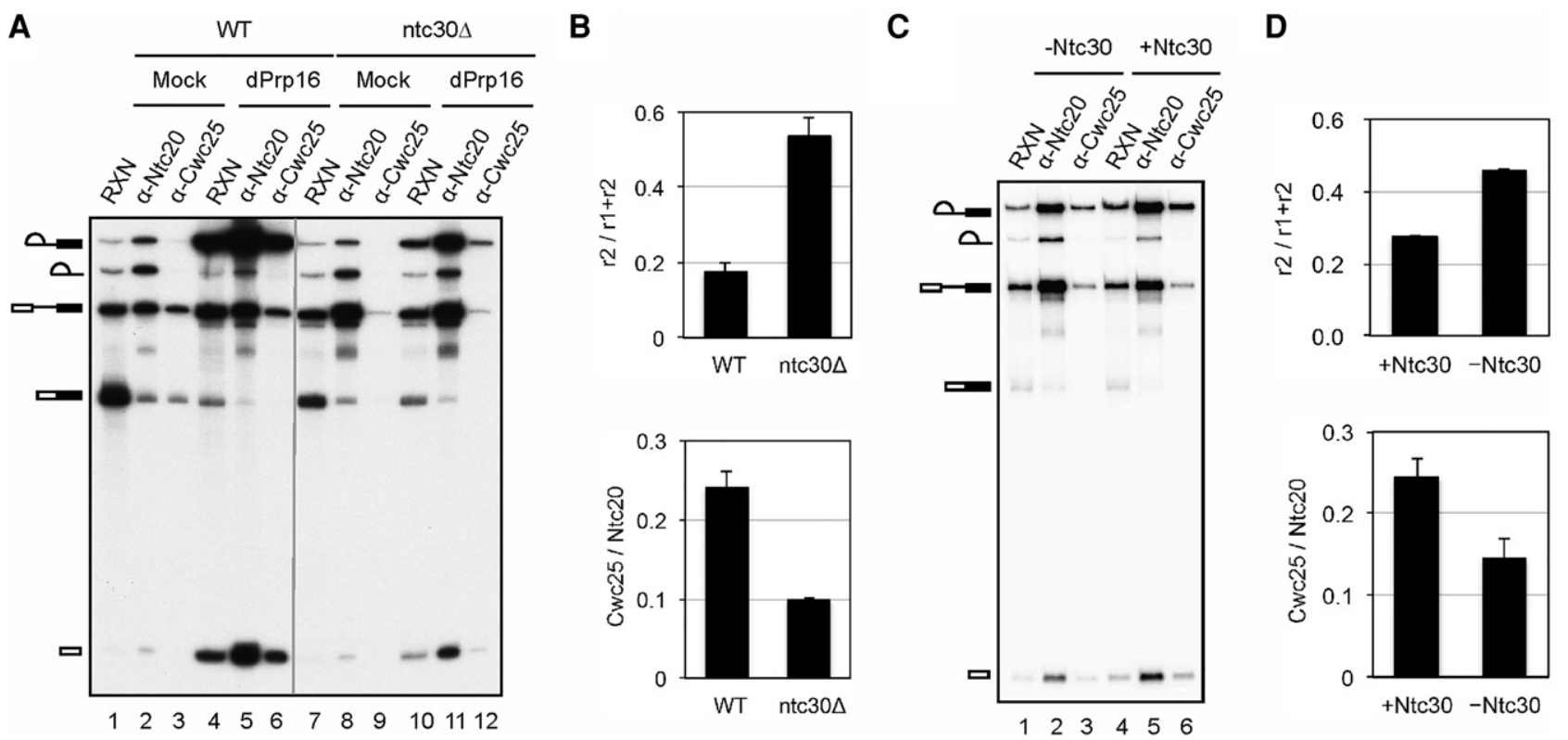

FIGURE 5. Ntc30 stabilizes the association of Cwc25 with the spliceosome. (A) Splicing was carried out in mock-treated (lanes 1-3 and 7-9) or Prp16-depleted (lanes 4-6 and 10-12) wild-type (lanes 1-6) or ntc30 (lanes 7-12) extracts, and the spliceosome was precipitated with antiNtc20 or anti-Cwc25 antibody. (B) Relative amounts of second reaction and Cwc25-associated spliceosomes were quantified and plotted in a bar graph. (C) The same as in A except splicing was carried out in Prp16-depleted ntc30 $\Delta$ extracts without (lanes 1-3) or with (lanes 4-6) prior addition of $40 \mathrm{ng}$ recombinant Ntc30. (D) RNA bands in $C$ were quantified and plotted in a bar graph as in $B$. (RXN) One-tenth of reaction mix; (dPrp16) Prp16 depletion.

higher in extracts depleted of both $\mathrm{Ntc30}$ and $\mathrm{Ntc2} 2$ (Supplemental Fig. S6B). These results suggest that the presence of $\mathrm{Ntc30}$ and/or Ntc20 stabilizes the association of Cwc25, and in the absence of either one or both, Cwc25 is more easily dissociated after the first reaction so that the pathway can proceed to the second step without needing Prp16.

\section{A model for spliceosome dynamics in the catalytic phase}

Based on the data presented here and published previously, we propose a model of spliceosome dynamics in the catalytic phase with free energy changes during transition from one step to the next (Fig. 6). Under normal splicing conditions (lower pathway), the spliceosome switches between closed (indicated by colored circle in the center of the spliceosome for binding of specific factors to the catalytic center at specific stages) and open (indicated by open circle in the center of the spliceosome for free of specific proteins binding to the catalytic center) conformational states. After activation, the spliceosome is in a stable closed conformational state with SF3a/b bound at the catalytic center (Pc, for precatalytic closed). Prp2 mediates destabilization of SF3a/b by hydrolyzing ATP to create an open conformational state (Po for precatalytic open) with a higher free energy level. The binding of Cwc25 lowers the free energy (purple line) and stabilizes the first-step conformation (Ic for step I closed) to promote the first reaction. The free energy level of the post-reaction state is presumed to be even lower as Cwc25 becomes tightly bound to the spli- ceosome after branch formation. Prp16 can stabilize the association of Cwc25 with the precatalytic spliceosome in an ATPindependent manner with branchpoint-mutated pre-mRNA (Tseng et al. 2011), presumably by lowering the energy level of the spliceosome. Upon binding, Prp16 can mediate dissociation of Cwc 25 from the precatalytic or post-F1 spliceosome by hydrolyzing ATP to create open conformational states of higher free energy (Po, or Io for the step I open, respectively). When the binding of Cwc25 to the spliceosome is weakened, such as in ntc30 $\Delta$, ntc $20 \Delta$, or ntc $30 \Delta 20 \Delta$ extracts, the free energy level of the Ic conformation is higher (dashed purple line), reducing the free energy difference between Ic and Io conformations. Consequently, transition from Ic to Io conformation is less dependent on ATP and Prp16.

The Io state allows repositioning of splice sites. An energy barrier exists for positioning the $3^{\prime}$ splice site to the catalytic center, and this barrier is lower when the distance between the $3^{\prime}$ splice site and the branchpoint is shorter, such as in Act7 pre-mRNA (dashed line). Slu7 and Prp18 can bind to the spliceosome with low affinity prior to the dissociation of Cwc25, and bind more tightly after the release of Cwc25 to position the $3^{\prime}$ splice site. Stable binding of Slu7/Prp18 lowers the free energy (blue green line) and stabilizes the second-step conformation (IIc for step II closed) in promoting the second reaction. Since Slu7/Prp18 bind tightly to the spliceosome even prior to exon-ligation, as in the case of splicing with $3^{\prime}$ splice site mutant pre-mRNA ACAC, occurrence of F2 may not further lower the free energy level. 

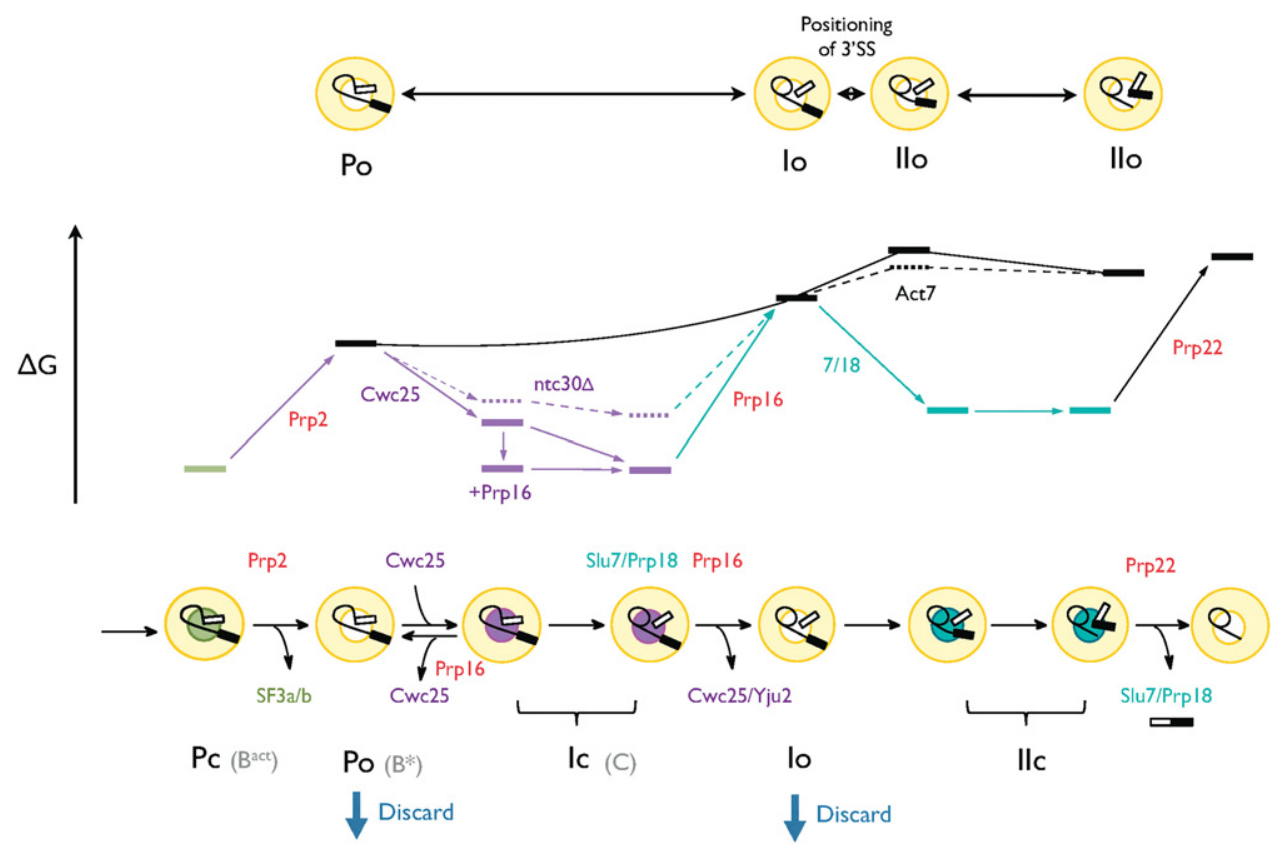

FIGURE 6. A thermodynamic model for spliceosome dynamics in the catalytic phase. White inner circles indicate open conformational states, and colored inner circles indicate closed conformational states with SF3a/b (light green), Yju2/Cwc25 (purple), or Slu7/Prp18/Prp22 (blue green) bound. Black lines represent the energy states of the top pathway, and black broken line represents the state using Act7 pre-mRNA. Colored arrows represent the energy states of the lower pathway. The purple broken line represents the energy state of the first catalytic step in ntc $30 \Delta$ extracts. (Po) Precatalytic open conformation; (Io) step 1 open conformation; (IIo) step 2 open conformation of Act7 pre-mRNA; (Pc) precatalytic closed conformation; (Ic) step 1 closed conformation; (IIc) step 2 closed conformation. Pc, Po, and Ic are equivalent to Bct, $\mathrm{B}^{*}$, and C complexes, respectively. Po and Io are susceptible to NTR-mediated disassembly (indicated as Discard).

The spliceosome formed in the absence of Cwc25 remains in the open conformational state after destabilization of SF3a/ $\mathrm{b}$, and it can fluctuate between different open conformational states (upper pathway), as the energy barrier is lower for the transition between different states (solid black line). The energy level of Po is proposed to be lower as R1 is extremely efficient in the absence of Cwc25. In contrast, F2 is much less efficient, presumably due to the energy barrier for positioning of the $3^{\prime}$ splice site.

\section{DISCUSSION}

Based on genetic and crosslinking data, a two-state conformational model of the catalytic spliceosome was proposed (Query and Konarska 2004; Konarska et al. 2006; Liu et al. 2007a; Smith et al. 2009). In this model, the spliceosomes in the first and second catalytic steps are in different conformations, which exist in equilibrium and are modulated by the interactions of splicing factors and splice sites. Such a hypothesis seems to contradict the notion of ATP being required for the transition from the first to second step in the in vitro splicing reaction (Schwer and Guthrie 1991). On the other hand, biochemical analysis of the purified spliceosome revealed the spliceosome being able to catalyze reverse splicing in both steps under various ionic conditions without the need of ATP. This suggests that the catalytic reactions might be directed by the conformation of the spliceosome, which may fluctuate between different states (Tseng and Cheng 2008). Here, we provide direct biochemical evidence for conformational equilibrium of the spliceosome in the catalytic phase under an open conformational state, and propose that the spliceosome may alternate between open and closed conformational states to facilitate the reaction under normal splicing conditions. By using a weak-binding Cwc25 variant, we were able to purify the first-step Cwc25-free spliceosome to homogeneity. We show that the purified spliceosome can catalyze splicing reactions in both forward and reverse directions when incubated in the splicing buffer without needing additional factors. This suggests that the Cwc25-free spliceosome is in a dynamic state able to switch between precatalytic, first-step and secondstep states, and the type of the chemical reaction that the spliceosome catalyzes is likely guided by the conformational state of the spliceosome. Genetic studies of PRP8 mutants have also suggested an "opened" form of the spliceosome to explain how Prp8, Prp16, and U6 may be involved in the transition from the first to second step (Liu et al. 2007a).

During normal splicing reactions, Cwc25 plays a central role in the transition from first to second step. Cwc25 is required for efficient first reaction (F1) (Chiu et al. 2009; Warkocki et al. 2009), but inhibits the second reaction (F2). Cwc25 is recruited and acts after Prp2-mediated spliceosome remodeling, which may create a high-affinity binding site for Cwc25 (Ohrt et al. 2012), but is detected mostly in association with splicing intermediates, suggesting that the 
reaction may take place immediately upon Cwc25 binding (Tseng et al. 2011). Supporting this notion, a study using single-molecule fluorescence resonance energy transfer to monitor the distance of the $5^{\prime}$ splice site and branchpoint in the first catalytic step has revealed fluctuation between different conformations in the $\mathrm{B}^{*}$ complex, which corresponds to Po (Fig. 6), and addition of Cwc25 increases proximity of the two sites to allow the chemical reaction (Krishner et al. 2013). Conceivably, Cwc25 stabilizes and drives equilibrium toward first-step conformation in facilitating F1 reaction. Its binding renders the spliceosome in a low free energy state, assuming a more rigid structure that prohibits conformational change. As a result, Cwc25 inhibits both F2 and R1 reactions. Cwc25 becomes tightly associated with the spliceosome after the reaction and requires Prp16-catalyzed ATP hydrolysis for its removal. It is worth noting that prevention of the reverse reaction is important to ensure efficient progression of the pathway during normal splicing reaction. However, on the purified Cwc25-free spliceosome, which presumably represents first-step spliceosome after the release of Cwc25, the F2 reaction occurred only inefficiently even with the addition of Slu7/Prp18, suggesting the existence of an energy barrier in positioning the $3^{\prime}$ splice site. This raises two questions as to splicing under normal conditions: how the spliceosome overcomes the energy barrier to catalyze the F2 reaction, which is facilitated by Slu7/Prp18, and how R1 is prevented after Cwc25 is removed mediated by Prp16. It is worth mentioning that the Cwc25-free spliceosome purified in this study is not identical to that generated in the normal splicing reaction in two aspects. First, Yju2 remains stably associated with our purified spliceosome (Fig. 2B), whereas it is destabilized together with Cwc25 mediated by Prp16 in the normal splicing pathway (Tseng et al. 2011). The presence of Yju2 might hinder conformational change on the spliceosome to promote efficient F2. Second, Slu7/Prp18 have previously been shown to associate with the spliceosome with lower affinities prior to the F1 reaction (Ohrt et al. 2013), but are not present on our purified spliceosome. Prior association of Slu7/Prp18 may facilitate efficient F2 upon the release of Cwc25 to prevent R1, and may also promote positioning of the $3^{\prime}$ splice site by lowering the energy barrier as well as stabilizing the second-step conformation in promoting F2. The removal of Slu7/Prp18 requires Prp22-catalyzed ATP hydrolysis, which also leads to mRNA release.

Prp16 was initially identified as a suppressor to branchpoint mutation and is proposed to play a role in splicing fidelity control by directing suboptimal spliceosomes to a discard pathway (Burgess and Guthrie 1993a, b; Koodathingal et al. 2010). Spliceosomes that stalled after Prp16 action have also been shown to be susceptible to disassembly mediated by NTR complex, consisting of Ntr1, Ntr2, and DEAHbox ATPase Prp43 (Mayas et al. 2010; Chen et al. 2013). In light of the functional role of Prp16 in mediating the release of Cwc25 and Yju2, the removal of Cwc25 and Yju2 from the catalytic center may be required for the spliceosome to enter the discard pathway by creating an open conformational state that is accessible to Prp43. Similarly, the open conformational state in the precatalytic step (Po) is also susceptible to NTRmediated spliceosome disassembly (Chen et al. 2013). Cwc25 is normally removed after branch formation, but can also be removed before branching if the reaction slows down due to mutations at the branch site or modification at the $5^{\prime}$ splice site, leading the spliceosome to the discard pathway (see Fig. 6; Koodathingal et al. 2010; Tseng et al. 2011). In the recently determined cryo-EM structures, Cwc25 was found to contact U6 snRNA as well as the branch site sequence in the catalytic center, and the $\mathrm{N}$ terminus of Cwc25 is inserted into the widened major groove of the bulged branch helix (Galej et al. 2016; Wan et al. 2016). Cwc25 may play a role in stabilizing specific RNA interactions in the catalytic core to promote the reaction. PRP16 shows extensive genetic interactions with $\mathrm{U} 2$ and $\mathrm{U} 6$, and was proposed to destabilize U2/ U6 helix I during transition from the first to second step (Madhani and Guthrie 1994; Mefford and Staley 2009). It is possible that destabilization of U2/U6 helix I is a consequence of Cwc25/Yju2 dissociation, which may induce rearrangement of RNA-RNA interactions at the active site.

In the cryo-EM structures, the $\mathrm{N}$-terminal residue $\mathrm{G} 2$ of Cwc25 was shown to make two $\mathrm{H}$-bonds with the branchpoint sequence and U6 snRNA, and the side chain of K10 donates a candidate $\mathrm{H}$-bond to the phosphate backbone of the branchpoint sequence (Galej et al. 2016; Wan et al. 2016), suggesting the importance of Cwc $25 \mathrm{~N}$ terminus for its function. Nevertheless, adding V 5 tags to the $\mathrm{N}$ terminus of Cwc25 does not impact splicing, although it weakens its association with the spliceosome. This suggests that stable association of Cwc25 with the spliceosome is not essential for efficient splicing, and the interaction of Cwc25 with the RNA catalytic core may not require specific sequences. It is conceivable that Cwc25 need not bind tightly to the spliceosome, since it only transiently associates with the spliceosome and has to leave after lariat formation. It will be interesting to see whether the $\mathrm{N}$ terminus of Cwc25, with tags added, is still positioned close to the branch helix, and how such transient interaction can promote specific interaction of the branch site with the $5^{\prime}$ splice site.

We have previously shown that splicing can proceed to the second step at a low efficiency in the absence of Prp16 when Yju2 is replaced with the $\mathrm{N}$-terminal half fragment of the protein, Yju2-N, in the splicing reaction (Chiang and Cheng 2013). Yju2-N is sufficient for its function in the first catalytic reaction, but has a much lower affinity for the spliceosome. Consequently, it is more easily dissociated from the spliceosome. Since Yju2 is required for stable association of Cwc25 with the spliceosome (Chiu et al. 2009), Cwc25 may be destabilized accordingly. Therefore, the spliceosome can exit from the closed conformational state more easily without Prp16. Likewise, we have observed an effect of Ntc30 on the stable association of Cwc25 with the spliceosome and on the efficiency of the second reaction in the absence of Prp16. It 
has previously been shown that deletion of NTC30 suppresses the growth defect of prp16-302 mutant (Villa and Guthrie 2005). We show here that the association of Cwc25 with the spliceosome is weakened when Ntc30 is absent. Splicing could progress to the second step without Prp16 to a certain extent in Ntc30-depleted and Ntc30/Ntc20 doubly depleted extracts, and the amount of the second reaction increased with decrease in the amount of the Cwc25-associated spliceosome. This provides a biochemical explanation for the suppression effect of $n t c 30 \Delta$ to prp16-302 mutation. Supporting this notion, the cryo-EM structures of the first-step spliceosome reveal that Ntc30, Cwc25, and Yju2 are located in the catalytic center of the spliceosome and interact with the RNA elements and Prp8 (Galej et al. 2016; Wan et al. 2016). Although direct interaction between Cwc25 and Ntc30 was not described, removing Ntc30 from its position could potentially alter the conformation of the catalytic core to destabilize Cwc25 association. The fact that splicing efficiency was slightly higher when Ntc30 was added back to ntc30 $\Delta$ extracts suggests facilitation of the first reaction by Ntc30, possibly by stabilizing Cwc25 association, but at the expense of more stringent requirements for Prp16 to progress to the second step.

Our results show that Cwc25 promotes the first reaction by stabilizing the first-step conformation, and its removal requires Prp16-mediated ATP hydrolysis so that Slu7/Prp18 can bind to the spliceosome with high affinity to promote the second reaction. In the absence of Slu7/Prp18, both Yju2 and Cwc25 can reassociate with the spliceosome upon depletion of ATP, suggesting that the binding of Yju2 and Cwc25 to the spliceosome is dynamic and reversible. During normal reactions, continuous ATP hydrolysis by Prp16 prevents Yju2 and Cwc25 from perpetual association with the spliceosome. The prior presence of Slu7/Prp18 before Yju2/Cwc25 are released may also prevent reassociation. Notably, while Slu7 and Prp18 form a heterodimeric complex and can bind to the spliceosome (James et al. 2002), Yju2 has to bind to the spliceosome first before $\mathrm{Cwc} 25$ can be recruited to the spliceosome (Chiu et al. 2009). Since Cwc25 is the key component that prevents the second reaction, this two-phase interaction might be less efficient for their rebinding to the spliceosome. Yju2 is not crucial in preventing the second reaction, but is destabilized from the spliceosome together with Cwc25 during Prp16 action. This may imply that Yju2 acts as an additional control in slowing down rebinding of Cwc25 to allow Slu7/Prp18 to function in a competitive manner so that the reaction can proceed to the second step.

\section{MATERIALS AND METHODS}

\section{Yeast strains}

BJ2168 (MATa prc1 prb1 pep4 leu2 trp1 ura3), YSCC14 (MATa prc1 prb1 pep4 leu2 trp1 ura3 PRP19HA NTC20::LEU2 NTC30:: URA3), YSCC15 (MATa prc1 prb1 pep4 leu2 trp1 ura3 PRP19HA NTC30::URA3), YSCC16 (MATa prc1 prb1 pep4 leu2 trp1 ura3 PRP19HA NTC20::LEU2).

\section{Splicing extracts and substrates}

Splicing extracts were prepared according to Cheng et al. (1990). The pre-mRNA substrates were prepared by in vitro transcription with SP6 RNA polymerase. For preparation of regular actin substrate, EcoRI linearized pSP64-88 plasmid was used as the template. Template for actin Act7 pre-mRNA was derived from pSP64-88 with deletion between the branchpoint and $3^{\prime}$ splice site as described in Brys and Schwer (1996).

\section{Immunoprecipitation and immunodepletion}

Immunoprecipitation of the spliceosome was performed as described in Tarn et al. (1993). For each 10-20 $\mu \mathrm{L}$ of splicing reaction mixtures, $10 \mu \mathrm{L}$ of protein A-Sepharose (PAS) conjugated with 1.5 $\mu \mathrm{L}$ of anti-Ntc20 antibody or $5 \mu \mathrm{L}$ of anti-Prp16 antibody was used. For precipitation of the V5-Cwc25- or Cwc25-HA-associated spliceosome, $1 \mu \mathrm{L}$ of anti-V5 antibody or $15 \mu \mathrm{L}$ of anti-HA antibody was used, respectively. For depletion of specific proteins from 100 $\mu \mathrm{L}$ of yeast extracts, $12.5 \mathrm{mg}$ of PAS was swollen in NET-2 buffer (50 mM Tris- $\mathrm{HCl}, \mathrm{pH} 7.4,150 \mathrm{mM} \mathrm{NaCl}, 0.05 \% \mathrm{NP}-40$ ) to make a bed volume of $50 \mu \mathrm{L}$, and used for conjugation with specific antibodies. For depletion of Prp16 and Yju2, $50 \mu \mathrm{L}$ of anti-Prp16 and $120 \mu \mathrm{L}$ of anti-Yju2 antibodies were used, respectively. For co-depletion of Slu7 and Prp22, $50 \mu \mathrm{L}$ of anti-Slu7 antiserum and $1.3 \mu \mathrm{g}$ of purified anti-Prp22 antibody were used. Each $100 \mu \mathrm{L}$ of extract was incubated with antibody-conjugated PAS at $4^{\circ} \mathrm{C}$ for $1 \mathrm{~h}$, and supernatants were collected as depleted extracts.

\section{Reactions on the precipitated spliceosome}

To chase the splicing reaction on the spliceosome, the spliceosome was precipitated with anti-V5 or anti-Ntc20 antibody conjugated to $10 \mu \mathrm{L}$ of protein A-Sepharose (see Supplemental Information). The beads were washed once with $1 \mathrm{~mL}$ of $10 \mathrm{mM}$ Tris- $\mathrm{HCl}, \mathrm{pH}$ 8.8 or 6.8 (for $\mathrm{pH}$ titration, $\mathrm{dH}_{2} \mathrm{O}$ was used in the final wash instead), and then incubated with $30 \mu \mathrm{L}$ of $10 \mathrm{mM}$ Tris- $\mathrm{HCl}, \mathrm{pH}$ 8.8 (or 6.8 , or 7.0 , or 7.4 , or 8.0 in specific experiments), $4 \mathrm{mM}$ $\mathrm{MgCl}_{2}$ (and $0.5 \mathrm{mM} \mathrm{MnCl}_{2}$ ), with or without $150 \mathrm{mM} \mathrm{KCl}$ at $25^{\circ} \mathrm{C}$ for $60 \mathrm{~min}$.

\section{Purification of recombinant Cwc25, Slu7, and Prp18}

Recombinant Cwc25 was expressed in E. coli with a His-tag at the C terminus by cloning CWC25 into the pET-22b plasmid vector and purified by chromatography on a Ni-Sepharose affinity column (Novagen). Slu7 proteins were expressed in E. coli and purified according to Chen et al. (2013). Prp18 was expressed in E. coli as His-Sumo-Prp18-HA fusion and purified by chromatography on a Ni-Sepharose column. The Sumo fragment was removed by cleavage of the fusion protein with Sumo-protease followed by chromatography on a Ni-Sepharose column.

\section{SUPPLEMENTAL MATERIAL}

Supplemental material is available for this article. 


\section{ACKNOWLEDGMENTS}

We thank D.S. Horowitz for careful comments on the manuscript, A. Peña for English editing, and members of the Cheng laboratory for helpful discussions. This work was supported by a grant from Academia Sinica and the Ministry of Science and Technology (Taiwan) (MoST103-2321-B-001-056).

Received September 16, 2016; accepted January 3, 2017.

\section{REFERENCES}

Ansari A, Schwer B. 1995. SLU7 and a novel activity, SSF1, act during the PRP16-dependent step of yeast pre-mRNA splicing. EMBO J 14: 4001-4009.

Brys A, Schwer B. 1996. Requirement for SLU7 in yeast pre-mRNA splicing is dictated by the distance between the branchpoint and the $3^{\prime}$ splice site. RNA 2: 707-717.

Burgess SM, Guthrie C. 1993a. A mechanism to enhance mRNA splicing fidelity: the RNA-dependent ATPase Prp16 governs usage of a discard pathway for aberrant lariat intermediates. Cell 73: 1377-1391.

Burgess SM, Guthrie C. 1993b. Beat the clock: paradigms for NTPases in the maintenance of biological fidelity. Trends Biochem Sci 18: 381-384.

Chen CH, Yu WC, Tsao TY, Wang LY, Chen HR, Lin JY, Tsai WY, Cheng SC. 2002. Functional and physical interactions between components of the Prp19p-associated complex. Nucleic Acids Res 30: 1029-1037.

Chen HC, Tseng CK, Tsai RT, Chung CS, Cheng SC. 2013. Link of NTR-mediated spliceosome disassembly with DEAH-box ATPases Prp2, Prp16 and Prp22. Mol Cell Biol 33: 514-525.

Cheng SC, Newman A, Lin RJ, McFarland GD, Abelson JN. 1990. Preparation and fractionation of yeast splicing extract. Meth Enzymol 181: 89-96.

Chiang TW, Cheng SC. 2013. A weak spliceosome-binding domain of Yju2 functions in first step and bypasses Prp16 in second step of splicing. Mol Cell Biol 33: 1746-1755.

Chiu YF, Liu YC, Chiang TW, Yeh TC, Tseng CK, Wu NY, Cheng SC. 2009. Cwc25 is a novel splicing factor required after Prp2 and Yju2 to facilitate the first catalytic reaction. Mol Cell Biol 29: 5671-5678.

Fica SM, Tuttle N, Novak T, Li NS, Lu J, Koodathingal P, Dai Q, Staley JP, Piccirilli JA. 2013. RNA catalyzes nuclear pre-mRNA splicing. Nature 503: 229-234.

Galej WP, Wilkinson ME, Fica SM, Oubridge C, Newman AJ, Nagai K. 2016. cryo-EM structure of the spliceosome immediately after branching. Nature 537: 197-201.

Horowitz DS, Abelson J. 1993a. Stages in the second reaction of pre-mRNA splicing: the final step is ATP independent. Genes Dev 7: 320-329.

Horowitz DS, Abelson J. 1993b. A U5 small nuclear ribonucleoprotein particle protein involved only in the second step of pre-mRNA splicing in Saccharomyces cerevisiae. Mol Cell Biol 13: 2959-2970.

James S, Turner W, Schwer B. 2002. How Slu7 and Prp18 cooperate in the second step of yeast pre-mRNA splicing. RNA 8: 1068-1077.

Jones MH, Frank DN, Guthrie C. 1995. Characterization and functional ordering of Slu7p and Prp17p during the second step of pre-mRNA splicing in yeast. Proc Natl Acad Sci 92: 9687-9691.

Konarska MM, Vilardeli J, Query CC. 2006. Repositioning of the reaction intermediate within the catalytic center of the spliceosome. Mol Cell 21: 543-553.

Koodathingal P, Novak T, Piccirilli JA, Staley JP. 2010. The DEAH box ATPases Prp16 and Prp43 cooperate to proofread 5' splice site cleavage during pre-mRNA splicing. Mol Cell 39: 385-395.

Krishner R, Blanco MR, Kahlscheuer ML, Abelson J, Guthrie C, Walter NG. 2013. Biased Brownian ratcheting leads to pre-mRNA remodeling and capture prior to first-step splicing. Nat Struct Mol Biol 20: 1450-1457.

Lardelli RM, Thompson JX, Yates JR III, Stevens SW. 2010. Release of SF3 from the intron branchpoint activates the first step of premRNA splicing. RNA 16: 516-528.
Linder P, Jankowsky E. 2011. From unwinding to clamping - the DEAD box RNA helicase family. Nat Rev Mol Cell Biol 12: 505-516.

Liu L, Query CC, Konarska MM. 2007a. Opposing classes of prp8 alleles modulate the transition between the catalytic steps of pre-mRNA splicing. Nat Struct Mol Biol 14: 519-526.

Liu YC, Chen HC, Wu NY, Cheng SC. 2007b. A novel splicing factor Yju2 is associated with NTC and acts after Prp2 in promoting the first catalytic reaction of pre-mRNA splicing. Mol Cell Biol 27: 5403-5413.

Madhani HD, Guthrie C. 1994. Genetic interactions between the yeast RNA helicase homolog Prp16 and spliceosomal snRNAs identify candidate ligands for the Prp16 RNA-dependent ATPase. Genetics 136: 677-687.

Mayas RM, Maita H, Semlow DR, Staley JP. 2010. Spliceosome discards intermediates via the DEAH box ATPase Prp43p. Proc Natl Acad Sci 107: 10020-10025.

Mefford MM, Staley JP. 2009. Evidence that U2/U6 helix I promotes both catalytic steps of pre-mRNA splicing and rearranges in between these steps. RNA 15: 1386-1397.

Ohrt T, Prior M, Dannenberg J, Odenwälder P, Dybkov O, Rasche N, Schmitzová J, Gregor I, Fabrizio P, Enderiein J, et al. 2012. Prp2-mediated protein rearrangements at the catalytic core of the spliceosome as revealed dcFCCS. RNA 18: 1244-1256.

Ohrt T, Odenwalder P, Dannenberg J, Prior M, Warkocki Z, Schmitzová J, Karaduman R, Gregor I, Enderlein J, Fabrizio P, et al. 2013. Molecular dissection of step 2 catalysis of yeast premRNA splicing investigated in a purified system. RNA 19: 902-915.

Query CC, Konarska MM. 2004. Suppression of multiple substrate mutations by spliceosomal prp8 alleles suggests functional correlations with ribosomal ambiguity mutants. Mol Cell 14: 343-354.

Schwer B, Gross CH. 1998. Prp22, a DExH-box RNA helicase, plays two distinct roles in yeast pre-mRNA splicing. EMBO J 17: 2086-2094.

Schwer B, Guthrie C. 1991. PRP16 is an RNA-dependent ATPase that interacts transiently with the spliceosome. Nature 349: 494-499.

Smith DJ, Konarska MM, Query CC. 2009. Insights into branch nucleophile positioning and activation from an orthogonal pre-mRNA splicing system in yeast. Mol Cell 34: 333-343.

Staley JP, Guthrie C. 1998. Mechanical devices of the spliceosome: motors, clocks, springs, and things. Cell 92: 315-326.

Tarn WY, Lee KR, Cheng SC. 1993. The yeast PRP19 protein is not tightly associated with snRNAs, but appears to associate with the spliceosome after binding of $\mathrm{U} 2$ to the pre-mRNA and prior to formation of the functional spliceosome. Mol Cell Biol 13: 1883-1891.

Toor N, Keating KS, Taylor SD, Pyle AM. 2008. Crystal structure of a self-splicing group II intron. Science 320: 77-82.

Tsai WY, Chow YT, Chen HR, Huang KT, Hong RI, Jan SP, Kuo NY, Tsao TY, Chen CH, Cheng SC. 1999. Ceflp is a component of the Prp19p-asociated complex and essential for pre-mRNA splicing. $J$ Biol Chem 274: 9455-9462.

Tseng CK, Cheng SC. 2008. Both catalytic steps of nuclear pre-mRNA splicing are reversible. Science 320: 1782-1784.

Tseng CK, Cheng SC. 2013. Spliceosome catalyzes debranching in competition with the reverse of the first chemical reaction. RNA 19: 971-981.

Tseng CK, Liu HL, Cheng SC. 2011. DEAH-box ATPase Prp16 has dual roles in remodeling of the spliceosome in catalytic steps. RNA 17: $145-154$.

Villa T, Guthrie C. 2005. The Isylp component of the NineTeen Complex interacts with the ATPase Prp16p to regulate the fidelity of pre-mRNA splicing. Genes Dev 19: 1894-1904.

Villa T, Pleiss JA, Guthrie C. 2002. Spliceosomal snRNAs: $\mathrm{Mg}^{2+}$-dependent chemistry at the catalytic core? Cell 109: 149-152.

Wahl MC, Will CL, Lührmann R. 2009. The spliceosome: design principles of a dynamic RNP machine. Cell 136: 701-718.

Wan R, Yan C, Bai R, Huang G, Shi Y. 2016. Structure of a yeast catalytic step I spliceosome at $3.4 \AA$ resolution. Science 253: 895-904.

Warkocki Z, Odenwälder P, Schmitzová J, Platzmann F, Stark H, Urlaub H, Ficner R, Fabrizio P, Lührmann R. 2009. Reconstitution of both steps of Saccharomyces cerevisiae splicing with purified spliceosomal components. Nat Struct Mol Biol 16: 1237-1243.

Will CL, Lührmann R. 2011. Spliceosome structure and function. Cold Spring Harb Perspect Biol 3: a003707. 

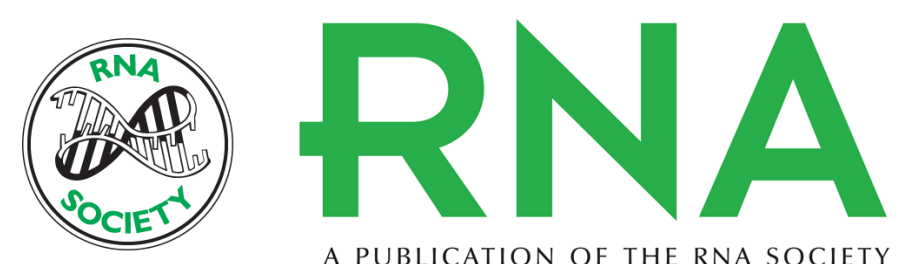

A PUBLICATION OF THE RNA SOCIETY

\section{A central role of Cwc25 in spliceosome dynamics during the catalytic phase of pre-mRNA splicing}

Chi-Kang Tseng, Che-Sheng Chung, Hsin-Chou Chen, et al.

RNA 2017 23: 546-556 originally published online January 5, 2017

Access the most recent version at doi:10.1261/rna.059204.116

\section{Supplemental Material}

References

Creative Commons License

Email Alerting
Service
http://rnajournal.cshlp.org/content/suppl/2017/01/05/rna.059204.116.DC1

This article cites 44 articles, 23 of which can be accessed free at: http://rnajournal.cshlp.org/content/23/4/546.full.html\#ref-list-1

This article is distributed exclusively by the RNA Society for the first 12 months after the full-issue publication date (see http://rnajournal.cshlp.org/site/misc/terms.xhtml). After 12 months, it is available under a Creative Commons License (Attribution-NonCommercial 4.0 International), as described at http://creativecommons.org/licenses/by-nc/4.0/.

Receive free email alerts when new articles cite this article - sign up in the box at the top right corner of the article or click here.

To subscribe to $R N A$ go to:

http://rnajournal.cshlp.org/subscriptions 